\title{
DESAIN SISTEM INFORMASI MANAJEMEN BERBASIS BORLAND DELPHI UNTUK PENGENDALIAN PERSEDIAAN PRODUK PADA UKM AAA
}

\author{
Andri $^{1}$, Arie Restu Wardhani ${ }^{2 *}$, Andy Hardianto ${ }^{3}$ \\ ${ }^{1,2,3}$ Program Studi Teknik Industri, Fakultas Teknik, Universitas Widyagama Malang \\ *Email Korespondensi : arierestu@widyagama.ac.id
}

\begin{abstract}
ABSTRAK
Desain sistem informasi manajemen pada UKM AAA ini bertujuan untuk memberikan kemudahan karyawan, manajer, dan pemilik UKM AAA dalam mengetahui stok persediaan barang, data konsumen, data supplier, dan laporan penjualan atau pembelian barang. UKM ini merupakan industri kecil yang merupakan distributor produk-produk sport yang pengelolaan sistem persediaannya masih bersifat manual. Pencatatan dilakukan dengan menggunakan buku besar dan perhitungan akumulasi persediaan masih menggunakan kalkulator. Selain sering mengalami kesulitan pada perhitungan persediaan barang dagang (produk), perusahaan juga sulit mencari data-data yang dibutuhkan dengan cepat seperti data penjualan dan pembelian. Berdasarkan permasalahan yang ada, maka dirancang sistem informasi manajemen untuk pengelolaan persediaan produk yang berbasis Borland Delphi 7.0 dan Microsoft Access 2010 sebagai databasenya. Hasil penelitian ini berupa sistem informasi persediaan barang dagang, untuk kebutuhan input data, akumulasi data dan pelaporan persediaan produk pada UKM AAA. Setelah dilakukan uji coba sistem baru, performansi pekerjaan karyawan dan pelayanan konsumen menjadi lebih cepat 8 menit dibandingkan dengan menggunakan sistem persediaan manual.
\end{abstract}

Kata kunci : Sistem informasi, sistem persediaan, Borland Delphi 7.0, Microsoft Access 2010

\section{ABSTRACT}

The management information system design for AAA SMEs aims to simplify the job of employees, managers, and the owner of the "AAA" SME in managing inventory stock, consumer data, supplier data, and sales or purchase reports. This small industry is a distributor of sports products which the system in managing inventory was manual. Currently, inputting the inventory data employs a ledger and the calculation of accumulated inventories utilises a calculator. The difficulties occur because many data such as sales and purchases data should be calculated. Also, it becomes difficult in searching particular data which should be found quickly. Based on the existing problems, the management information system is designed for product inventory management based on Borland Delphi 7.0 and Microsoft Access 2010 as its database. This study yields the inventory information system which comprises data input, data accumulation and product inventory report of " $A A A$ " SME. After testing the new system, the performance is improved by about 8 minutes faster than using $a$ manual inventory system.

Keywords : Information system, inventory system, Borland Delphi 7.0 and Microsoft Access 2010

\section{PENDAHULUAN}

Sistem informasi terutama pada saaat era industri 4.0 saat ini sangat penting untuk mengelola berbagai bidang yang sudah terkait dengan internet. Implementasi SIM dapat terdiri dari bentuk yang sederhana sampai dengan rumit disesuaikan dengan kebutuhan (Jogiyanto, 1999). Hampir di semua perusahaan sudah memanfaatkan sistem informasi untuk pengolahan data dan peninjauan laporan, karena dengan adanya sistem informasi, pekerjaan menjadi lebih cepat dan tepat.

UKM AAA merupakan usaha yang bergerak di bidang penjualan atribut olahraga, mulai dari jaket, sepatu, kaos sampai dengan celana olahraga. Untuk memenuhi kebutuhan konsumen yang memiliki beragam selera, UKM AAA ini menyediakan produk yang 
beragam sangat banyak. Namun pengolahan data persediaan masih dengan cara pembukuan manual.

Kendala yang sering terjadi diantaranya adalah pendataan yang sangat lambat dari segi pengontrolan stok produk (Kroenke, 2008). Sebagai contoh, pencatatan persediaan barang dalam satu bulan rata-rata sebanyak 300 pasang, jaket 500 pcs, kaos 700 pcs dengan berbagai merk (nike, adidas, joma, dsb. Kendala lain adalah kesulitan pencarian data seperti alamat konsumen untuk pengiriman barang dan kesulitan mencetak tagihan, karena faktur berbentuk lembaran kertas yang terpisah-pisah. Hal ini tentu saja menghambat proses penjualan yang dilakukan setiap hari. Proses pengecekan barang membutuhkan waktu yang cukup lama, karena harus melihat satu per satu data persediaan barang pada buku. Sehingga membuat konsumen menunggu, tentu saja berpengaruh pada pelayanan yang diterima oleh konsumen. Jadi, untuk mengatasi kendala-kendala teresbut, maka diperlukan suatu sistem informasi yang dapat mendukung pengolahan data barang, konsumen, supplier, laporan pembelian dan laporan penjualan secara komputerisasi. Oleh karena itu, penelitian ini bertujuan untuk merancang sistem informasi persediaan barang dagang berbasis Borland Delphi 7.0 yang efisien pada UKM AAA.

\section{METODE}

Metode yang digunakan pada masalah ini dapat digambarkan sesuai diagram alir seperti pada Gambar 1 .

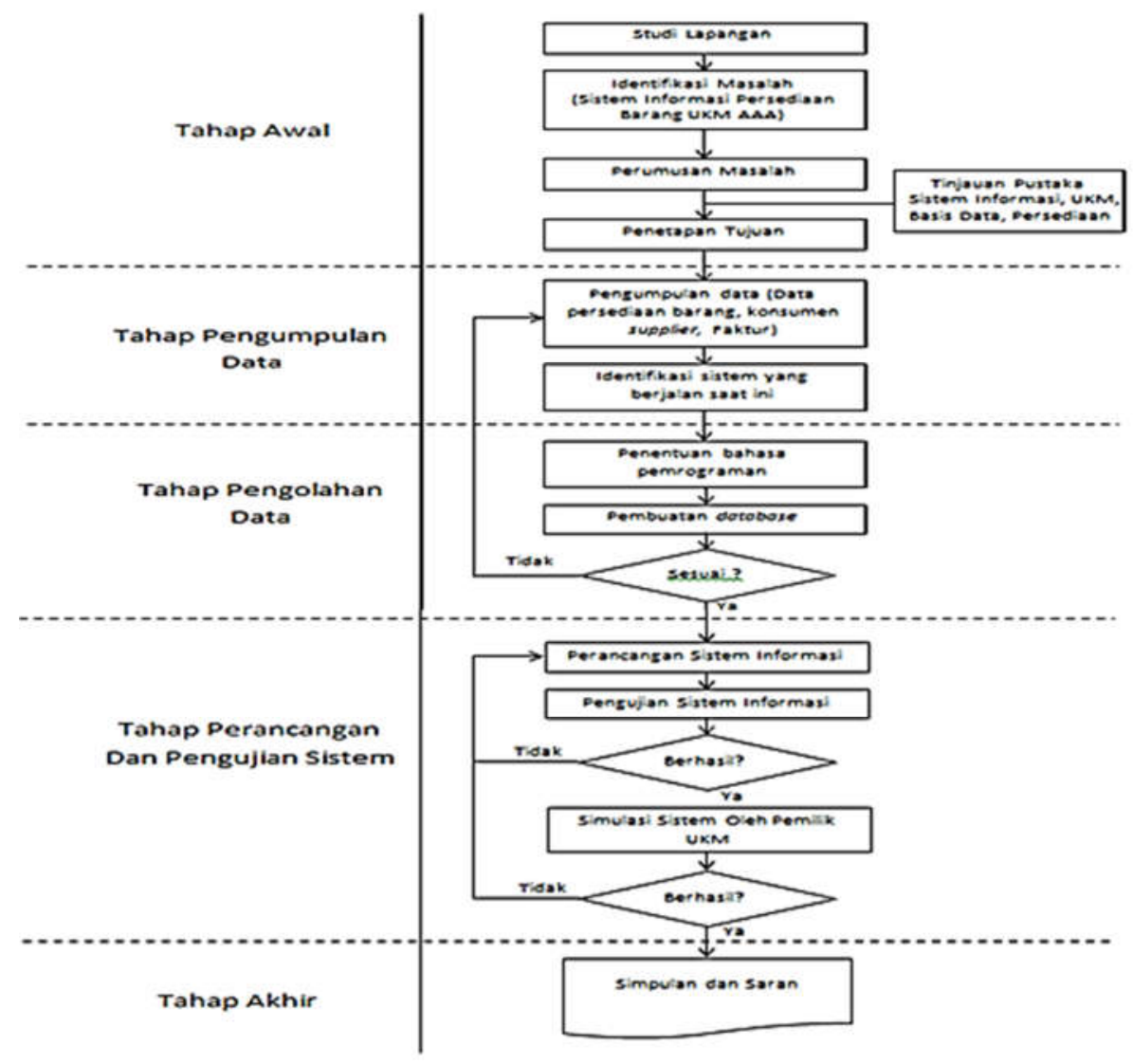

Gambar 1. Diagram Alir

\section{8}




\section{Tahap Awal}

Pada tahap ini dilakukan analisis masalah yang ada pada UKM AAA. Kemudian peneliti menentukan apakah masalah tersebut dapat diperbaiki sehingga kegiatan usaha UKM AAA menjadi lebih efisien. Masalah yang ada kemudian diidentifikasi untuk mengetahui data apa saja yang diperlukan, proses pengolahan sampai dengan hasil dari rancangan perbaikan yang akan diberikan

\section{Tahap Pengumpulan Data}

Setelah mengidentifikasi masalah, dapat diketahui data apa saja yang diperlukan dalam penelitian. Untuk memperoleh data yang diperlukan tersebut, dilakukan pengumpulan data dengan cara observasi dan wawancara. Observasi dilakukan secara langsung pada UKM AAA. Untuk wawancara juga dilakukan langsung pada UKM AAA dengan narasumber pemilik UKM AAA.

\section{Tahap Pengolahan Data}

Data yang sudah terkumpul diolah untuk dilakukan proses perbaikan. Pengolahan data yang pertama yakni pembuatan diagram konteks, untuk mengetahui data apa yang harus dimasukkan dan informasi apa yang didapat dari sistem yang ada. Kedua, perancangan data flow diagram (DFD) untuk menggambarkan arus data pada sistem yang akan dibentuk. Ketiga, perancangan entity relationship diagram (ERD) untuk mengetahui hubungan antar entitas dalam sistem.

\section{Tahap Perancangan dan Pengujian Sistem}

Setelah pengolahan data selesai, perancangan dimuai dari pemilihan bahasa pemrograman. Kemudian menerapkan hasil pengolahan data pada perancangan sistem. Setelah terbentuk suatu sistem, dapat dilakukan pengujian secara individu, lalu dilanjutkan pengujian pada UKM AAA secara langsung.

\section{Tahap Akhir}

Tahap terakhir penelitian yakni pembuatan simpulan dan saran. Setelah dilakukan pengujian oleh pemilik UKM dan dianggap sesuai dengan kebutuhan, maka penelitian dianggap selesai. Dari sistem yang sudah dihasilkan, dapat diminta evaluasi pada user tentang apa yang bisa dikembangkan lagi untuk dimasukkan sebagai saran penelitian.

\section{Perancangan Hardware}

Sistem informasi persediaan barang akan dirancang semudah mungkin untuk dioperasikan. Pertama user diminta untuk memasukkan username dan password untuk masuk pada sistem. Kemudian muncul menu utama dengan beberapa sub-menu. Lebih jelasnya bisa dilihat pada flowchart rancangan sistem di Gambar 2.

\section{Diagram Aliran Data}

Pada perancangan sistem informasi persediaan barang UKM AAA. Ditampilkan pula struktur diagram aliran data dari program yang ada pada sistem untuk mempermudah memahami fungsi dari setiap program pada sistem ini dapat digambarkan pada Gambar 3.

\section{Perancangan Diagram Konteks}

Diagram konteks pada perancangan sistem informasi persediaan barang ini dibuat untuk menggambarkan aliran proses secara umum diantara semua personil yang bersangkutan. Diagram ini menggambarkan secara umum proses input baik dari kasir, administrasi, maupun gudang sampai kepada pemilik UKM. 


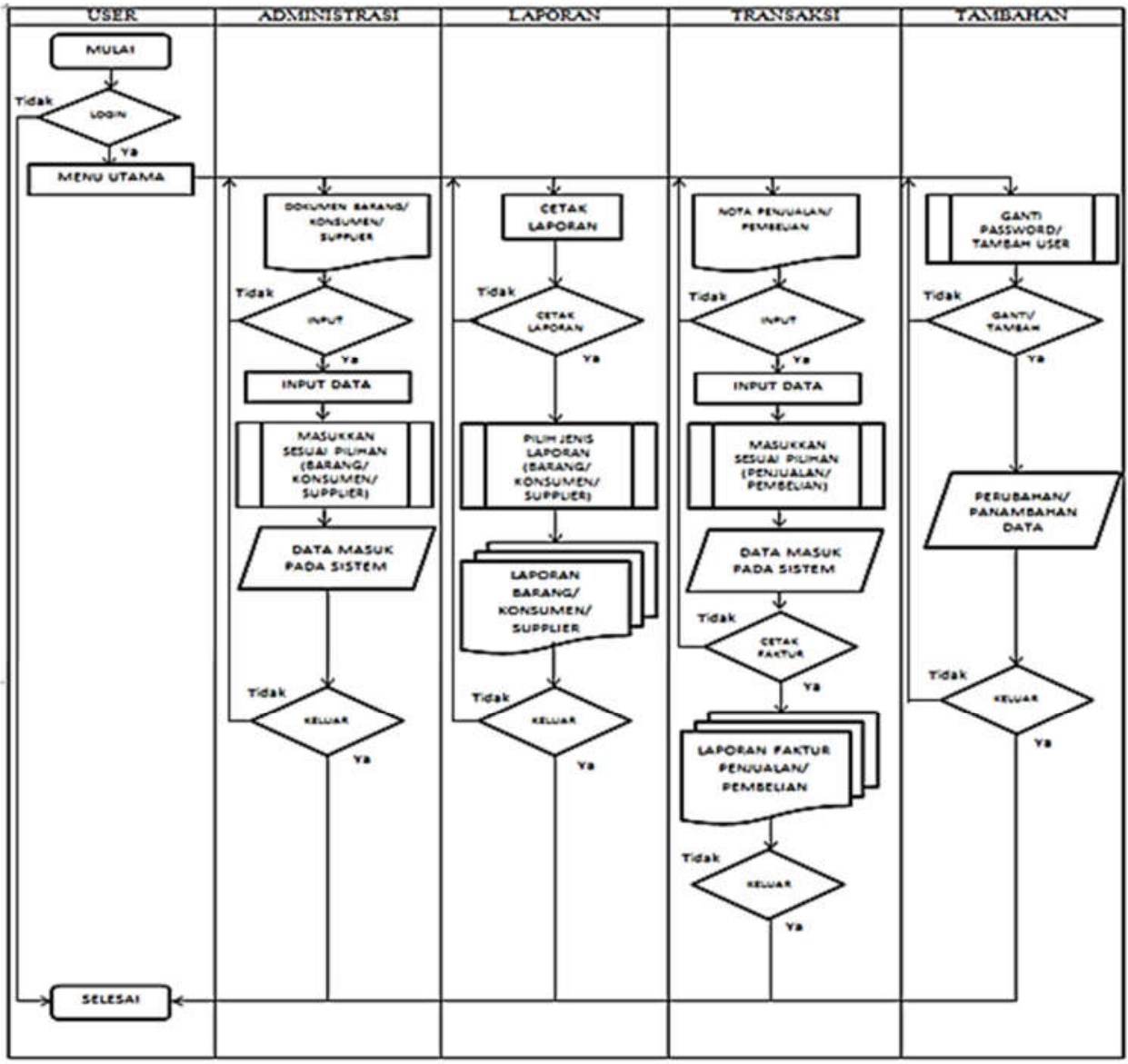

Gambar 2. Flowchart Rancangan Sistem

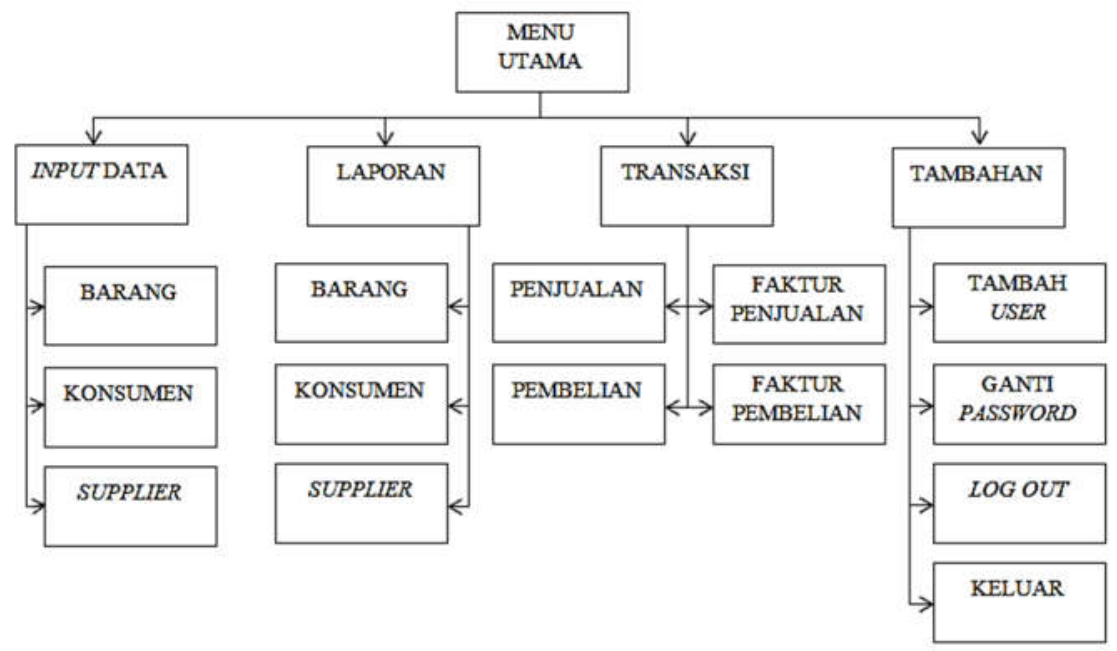

Gambar 3. Diagram Aliran Data Sistem 


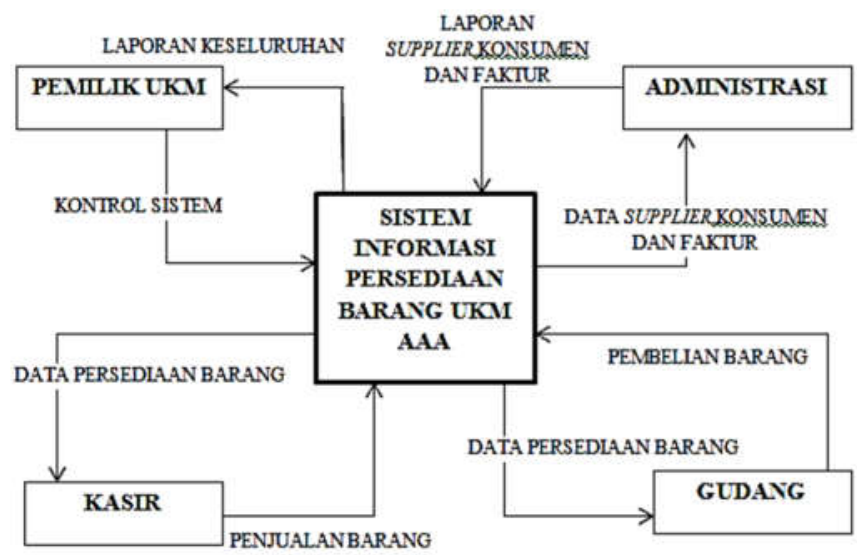

Gambar 4. Diagram Konteks Sistem

\section{Perancangan Data Flow Diagram (DFD)}

DFD dibuat untuk menggambarkan arus data dari sebuah sistem. Pada sistem informasi yang akan dirancang ini mempunyai gambaran DFD sebagai berikut.

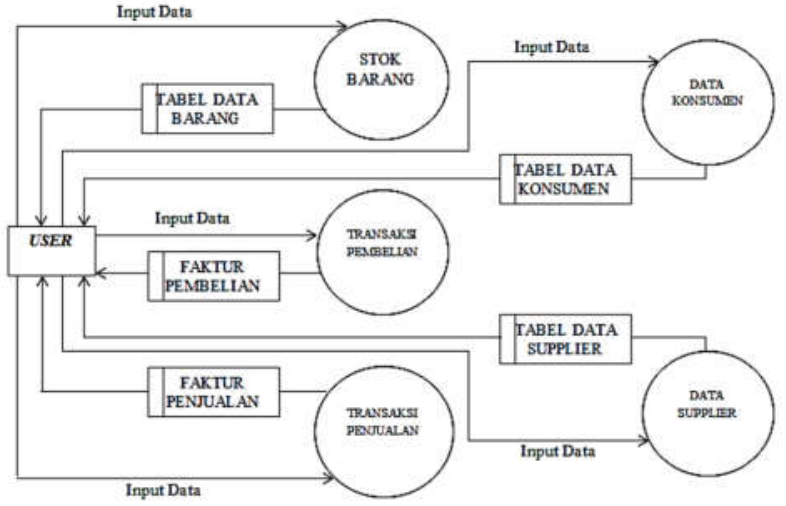

Gambar 5. DFD Rancangan Sistem

\section{Perancangan ERD (Entity Relationship Diagram)}

Dalam sistem informasi ini terdapat beberapa entitas. Untuk menggambarkan hubungan atau relasi antar entitas, dibuat sebuah diagram dan tabel ERD agar lebih memudahkan pembahasan perancangan sistem ini.

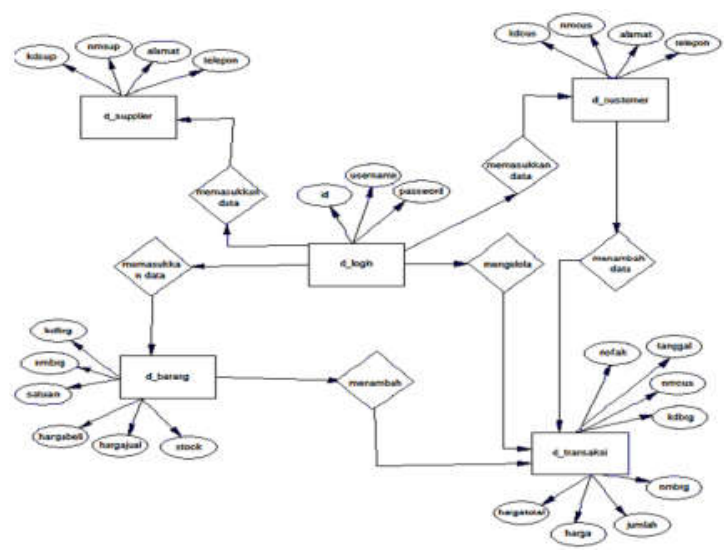

Gambar 6. Perancangan ERD Sistem 


\section{Perancangan Interface Sistem}

Berikut perencanaan interface sistem informasi persediaan barang yang akan diusulkan pada UKM AAA dapat dilihat pada Gambar 7-13.

\section{Menu Login}

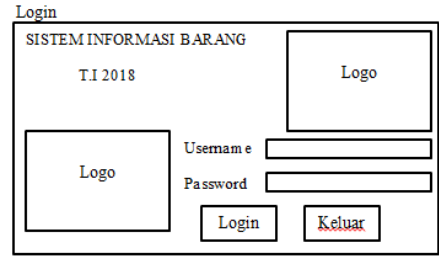

Gambar 7. Rancangan Menu Login

\section{Menu Utama}

\section{Form Data Barang}

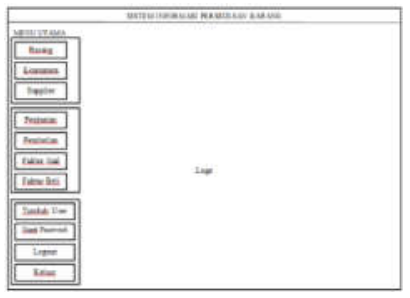

Gambar 8. Rancangan Menu Utama

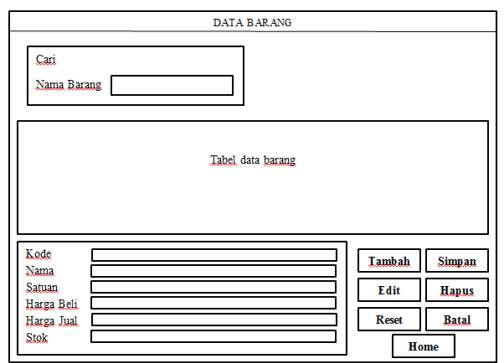

Gambar 9. Rancangan Form Data Barang

\section{Form Transaksi Penjualan}

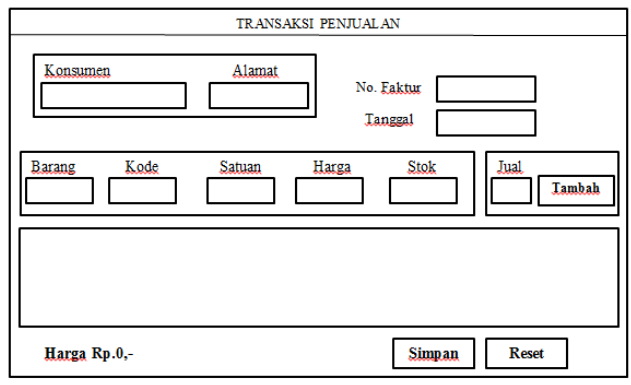

Gambar 10. Rancangan Form Transaksi Penjualan

Form Laporan Persediaan Barang

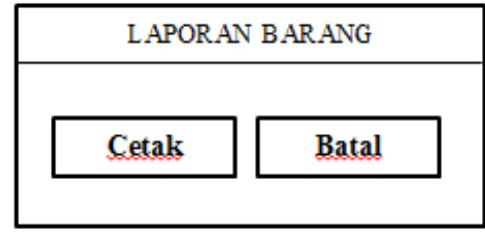

Gambar 11. Rancangan Form Laporan Persediaan Barang 


\section{Pengujian Tampilan Interface Sistem}

Berikut merupakan pengujian tampilan interface sistem setelah dilakukan proses pengerjaan menngunakan Borland Dephi 7.0 sesuai perancangan yang sudah dikerjakan.

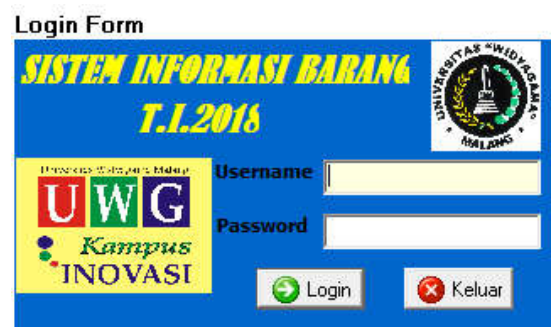

Gambar 12. Tampilan Login

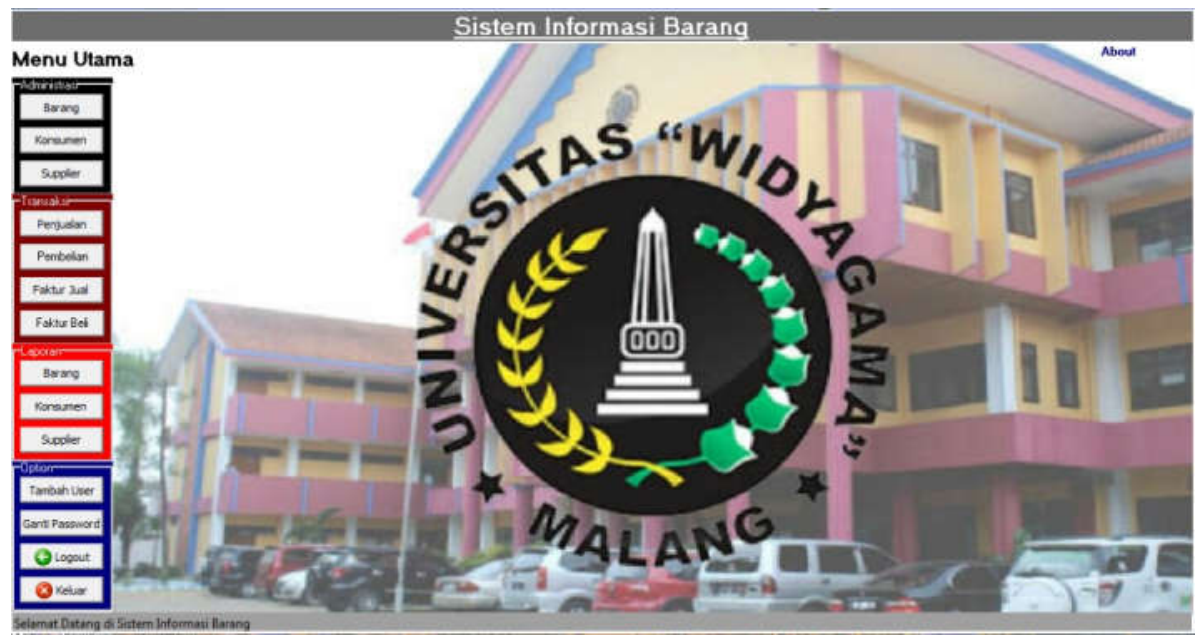

Gambar 13. Tampilan Menu Utama

\section{HASIL DAN PEMBAHASAN}

Hasil yang dipeoleh adalah sistem informasi manajemen yang mempercepat proses pendataan dan pelaporan persediaan produk (Maulana, 2015). Selain itu, pencarian data, dan perhitungan jumlah persediaan serta biaya persediaan dapat diperoleh dengan cepat.

Sistem informasi yang telah diimplementasikan terbukti dapat membantu meningkatkan performansi pekerjaan karyawan dan pelayanan konsumen dengan nilai efisiensi yang lebih tinggi dibandingkan dengan sistem manual sebelumnya, bila sebelumnya dibutuhkan waktu \pm 10 menit untuk menemukan produk tertentu, setelah menggunakan sistem informasi hasil penelitian hanya membutuhkan waktu \pm 2 menit saja.

Kemudian dokumentasi dan pengarsipan seluruh berkas administrasi dapat terkontrol dengan adanya sistem informasi, karena dalam sistem ini data sudah diklasifikasikan sesuai kebutuhan karyawan atau pemilik UKM. Dan yang terakhir, sistem informasi dirancang sesederhana mungkin agar mempermudah pengguna dalam pengoperasian, serta sudah dilakukan uji coba dan implementasi pada UKM AAA.

\section{DAMPAK DAN MANFAAT}

Perancangan sistem informasi yang dapat mendukung UKM diharapkan mampu meningkatkan produktivitas kerja UKM terutama dalam pengelolaan persediaan (Minarni \& Susanti, 2014). Pengendalian persedian ini mencakup pendataan barang masuk maupun 
barang keluar serta biaya dan waktu dapat dikelola secara cepat dan tepat, serta dapat mengurangi penumpukan dokumen yang tentunya lebih ramah lingkungan. Borland Delphi dan Microsoft Access digunakan sebagai software yang membangun database. Software ini tergolong mudah dipelajari, sehingga dimasa yang akan datang, user dalam hal ini karyawan, manajer dan pemilik UKM mampu memperbaiki software sesuai dengan kebutuhan, bahkan dapat memperbaiki sistem jika terjadi eror/ kegagalan sistem.

\section{KESIMPULAN}

Berdasarkan hasil penelitian, terdapat beberapa kesimpulan yang dapat diambil dari perancangan sistem informasi persediaan barang dagang pada UKM AAA yaitu, Pertama sistem informasi yang telah diimplementasikan terbukti dapat membantu meningkatkan performansi pekerjaan karyawan dan pelayanan konsumen dengan nilai efisiensi yang lebih tinggi dibandingkan dengan sistem manual sebelumnya, bila sebelumnya dibutuhkan waktu \pm 10 menit untuk menemukan produk tertentu, setelah menggunakan sistem informasi hasil penelitian hanya membutuhkan waktu \pm 2 menit saja.

Kedua, dokumentasi dan pengarsipan seluruh berkas administrasi dapat terkontrol dengan adanya sistem informasi (Nugrahanti \& Fatim., 2015), karena dalam sistem ini data sudah diklasifikasikan sesuai kebutuhan karyawan atau pemilik UKM. Dan yang terakhir, sistem informasi dirancang sesederhana mungkin agar mempermudah pengguna dalam pengoperasian, serta sudah dilakukan uji coba dan implementasi pada UKM AAA.

Dalam perancangan sistem informasi persediaan barang dagang UKM ini dapat diberikan saran-saran untuk pengembangan sistem lebih lanjut antara lain. Pertama, pengembangan sistem dapat dilakukan dengan memisahkan hak akses sesuai masing-masing bagian, kasir hanya untuk penjualan, gudang hanya untuk pembelian, administrasi untuk rekap laporan dan pemilik UKM dapat mengontrol semua proses tersebut.

Kedua, Sistem informasi ini juga dapat dikembangkan dengan memberikan koneksi web bila UKM sudah berkembang di berbagai daerah, agar dapat terhubung antara satu UKM dengan UKM cabang yang lain. Dan yang terakhir, sistem informasi dapat dikembangkan dengan fitur laporan keuangan yang terintegrasi, agar memudahkan pembuatan laporan keuangan setiap periodenya.

\section{UCAPAN TERIMA KASIH}

Kami sangat berterimakasih pada UKM AAA, ketua program studi Teknik Industri, dosen pembimbing, serta seluruh pihak yang membantu terselesaikannya penelitian ini.

\section{REFERENSI}

Jogiyanto, H. M. (1999) 'Analisis dan Desain Sistem Informasi: Pendekatan Terstruktur Teori dan Praktek Aplikasi Bisnis', Yogyakarta: Andi.

Kroenke, D. M. (2008) 'Experiencing Mis', Prentice-Hall, Upper Saddle River, NJ https://id.wikipedia.org/wiki/Sistem_informasi (diakses tgl 11-okt-2018 pukul 20:15)

Maulana, R. T. (2015) 'Pengembangan Sistem Informasi Manajemen Inventori Bengkel dan Laboratorium dengan Program Delphi di SMK Muhammadiyah Prambanan', Skripsi, Fakultas Teknik. Universitas Negeri Yogyakarta.Yogyakarta.

Minarni, S. (2014). 'Sistem Inventori Obat pada Rumah Sakit Umum Daerah (RSUD) Padang', Jurnal Momentum, 16(1), 103-111.

Nugrahanti, F. (2015) 'Perancangan Sistem Informasi Inventory Sparepart Mesin Fotocopy dengan Menggunakan Visual Delphi 7 (Studi Kasus di UD. Eka Taruna Madiun)', Seminar Nasional Teknologi Informasi dan Komunikasi 2015 (SENTIKA 2015), Yogyakarta, 28 Maret. 
Sidharta, L. (1995) 'Pengantar Sistem Informasi Bisnis', Jakarta: PT. Elex Media Komputindo. 